\title{
Car Sharing Versus Car Ownership: An Exploratory Examination in India
}

\author{
Aditi Naidu, K.Rajagopal, Manish Sinha, Vaishali Mahajan
}

\begin{abstract}
Sharing economy is a relatively recent development in emerging economies such as India.Sharing economy has been conceptualized to include integrated collaboration in peer to peer commercial exchange of mostly underutilized goods and services for a fee, on a non-ownership basis (Altinat and Taheri, 2019)[1]; a business model consisting of a firm, primarily a service enabler such as Airbnb that acts as an intermediary between the supplier and customers of such goods and services (Kumar, et al, 2018); often referred to as collaborative consumption facilitated by online platforms (Guyader, 2018) [2]. While enjoyment and economic reward in terms of cost savings have been reported in studies as motivators for the use of such access-based services (Lee et al., 2018) [3], collaborative consumption has also been reported to being considered as an alternative ecological mode of consumption (Gopalakrishnanand Matthews,2018) [4].The two prime factors: supply-side flexibility and technology innovations have been enabling the steep growth of peer-to-peer platforms predominantly. The process of market entry for suppliers has been streamlined effectively by the technology innovations and has also made possible the searchable listings for the consumers resulting in keeping the overheads low and intact. The supply-side flexibility is yet another milestone achievement in terms of these shared platform which enables the Uber drivers to add or remove themselves from the available supply of drivers by a mere swipe of their mobile app. The same is the option for the provider who can voluntarily list or delist the offerings of their goods or services as per their wish. As an optimum solution to these problems, online shopping portals provide customers with reliable replacement policies and often refund cash in case of dissatisfaction.
\end{abstract}

Key Words: E-commerce business, consumer Post purchase, and online shopping

Like many other developing countries, India, a major emerging economy has its cities facing heavy traffic congestion on its roads, so much so that, apart from being frustrating to the commuters, these traffic congestions cost India's biggest cities monetary losses up to $\$ 22$ billion annually wherein cost of congestion has been calculated based on fuel burned, productivity lost, man hours and opportunity cost, pollution as well as accidents or other health costs incurred on an annual basis (www.scroll.in). This traffic congestion is expected to worsen with rapid urbanization and increase in vehicle ownership (www.economictimes.com).Sharing economy, with

Revised Manuscript Received on September 10, 2019.

Aditi Naidu, Marketing department, Symbiosis Centre for Management and Human Resource Development, Symbiosis International (Deemed), Pune, Maharashtra, India.

(Email: aditi_naidu@scmhrd.edu)

K.Rajagopal, Marketing department, Symbiosis Centre for Management and Human Resource Development, Symbiosis International (Deemed), Pune, Maharashtra, India.

(Email: k_rajagopal@scmhrd.edu)

Manish Sinha, General management department, Symbiosis Centre for (Deemed), Pune, Maharashtra, India.

(Email: manish_sinha@scmhrd.edu)

Vaishali Mahajan, Marketing department, Symbiosis Centre for Management and Human Resource Development, Symbiosis International (Deemed), Pune, Maharashtra, India.

(Email: vaishali_mahajan@scmhrd.edu) Management and Human Resource Development, Symbiosis Internationa

various car sharing platforms such as Uber, Ola, Drivezy could be an answer to this increasing burden on the city roads. The market valuation in terms of ridesharing of Uber(MacMillan and Demos 2015)[5] and extent of penetration in the market(DePillis 2013)[6] is an evidence for the growing importance attached to sharing economy in the mobility sector. Uber for instance has made headway entry into more than 60 countries and 400 cities across the globe as of 2018. As per the official announcement of Uber in 2014,the number of drivers (associated with them) who were in their official list (in US) was 160,000 and in 2015 and 2017 the number surged to 3,27,000 and 1.3 million respectively.

Key Words: Shared Economy, Car Sharing and Shared Mobility

\section{INTRODUCTION}

While India is recognized as a fast-emerging economy, the country's urban landscape is facing challenges of surging traffic leading to worsened traffic congestion, fuel wastage, pollution concerns, longer commutes, parking problems (Goyal, 2018) [7]. Apart from being frustrating to the commuters, these traffic congestions cost India's biggest cities monetary losses up to $\$ 22$ billion annually wherein cost of congestion has been calculated based on fuel burned productivity lost, man hours and opportunity cost, pollution as well as accidents or other health costs incurred on an annual basis (www.scroll.in, 2019). This traffic congestion is expected to worsen with rapid urbanization and increase in vehicle ownership.

Furthermore, a recent study by the World Health Organization spells out the catastrophic levels to which India's pollution levels have reached, such that transportation, accounting for about $11 \%$ of the country's carbon emissions, is a major source of pollution in several cities nationwide such that, with as many as, 14 of 20 most polluted cities in the world, 14 are in India (Singh, 2019) [8]

Against this grim background, the country is on the verge of a new development: that of the emergence and adoption of car pooling and ride sharing options such as Uber and Ola (Goyal, 2018) [9] with an Uber commissioned BCG report claiming more than 79 percent of prospective car buyers in the country may refrain from buying a car if ridesharing matches car ownership for affordability and convenience (www.newindianexpress.com, 2018)

The sharing economy- conceptualized to include integrated collaboration in peer to peer commercial exchange of mostly underutilized goods and services for a fee, on a non-ownership basis (Altinat and Taheri, 2019) [1] a business model consisting of a firm, primarily a service enabler such as Airbnb that acts as an intermediary between 
the supplier and customers of such goods and services (Kumar, et al, 2018)[10] is a relatively recent development in India with prominent business periodicals recognizing car sharing as a disruptive force for the country's auto-sector by reporting more and more Indian customers adopting car sharing solutions for their daily commute.

With the recent introduction of various car sharing apps such as Ola, Uber, Zoom car, Revv, sRide in India, and their enthusiastic uptake by the Indian consumers as per various reports and periodicals, this study, attempts to assess the extent of two specific car sharing services: Uber and Ola on the sale of car ownership in India. Set in India, this study is similar in its objectives as prior studies (Zervas, Proserpio, and Byers, 2014 ; Camilleri and Neuhofer, 2017) [11][12] that demonstrated the impact of sharing economy as a disruptive factor affecting traditional industries.

Being, to the best of the knowledge of the authors, the first of its kind in India, this study begins and primarily answers the following questions:

1 . Is the Indian consumer preferring car sharing services to car ownership?

2. Are car sharing services such as Ola and Uber, influencing car ownership as reflected by car sales in the country?

An exploratory study, the study uses a mix of qualitative and quantitative methods to develop an understanding on the impact of sharing economy- particularly in ride sharing on car ownership. From the qualitative angle, the study begins to explore the phenomenon of sharing economy versus ownership via literature review and developments in the area as reported in respected news periodicals in the country. To extend the study further, a statistical analysis is carried out to examine if data on car sales over the past years indicates an impact of ride sharing services such as Ola and Uber on historical car sales data.

The study primarily has two major contributions: in assessing the phenomenon of the sharing economy in the context of India, the study advances research on this phenomenon in the context of a major emerging economy: with most of the research in the area carried out in the developed economies context. Secondly, the study findings may present implications to the industry: the automobile industry in particular, as to the ramifications to their business as well as the way forward.

\section{LITERATURE REVIEW}

A. Access based conception of Products and services by the consumers:

The current trend of consumer consuming a product or service is not by owning the products or services but by way of getting access to the product and services through rental and pay for the benefits derived for a particular period of time (Lovelock 2004)

In the processes of acquiring the product or service the consumer shows the willingness towards paying a price equivalent to the benefits derived out of the service or product availed through rental (Durgee and O'Connor 1995) [13].The processes of rental also helps the consumers to access the products and service which are of high prized, scarce otherwise are beyond their affordability if they want to buy or own.(Gummesson 2004) [14]. There are different dimensions and facets for the access based conception, of which the six dimensions are considered to be the prime: anonymity, political consumerism, temporality, consumer involvement, market mediation and the type of accessed object. In the access mechanism the consumers is at liberty to pay only for the experience derived out of the product and not for owning the product which may or may not be viable and expensive otherwise.(Chen 2009) [15].The access of product and service model is not really a new concept, consumers have been experiencing these models since ages in the form of using a share public transport system and paying just for the distance traveled, the books shared from the library for a duration of time, the DVDs borrowed from the DVD shops for a particular time frame and so on (Belk 2010: Gansky 2010) [16][17].However the model of accessing and sharing the product and services is getting popular and more and more number of consumers have started resorting to the model because of easy availability of the services and products propelled by the advent of the easy internet access in particular and Information technology in general.(Rifkin 2000,Roger 2010) [18][19].

Studies have clearly identified the rapid growth of the sharing economy, a technology enabled economic phenomenon which encourages access over ownership (Trenz et al., 2018) [20]; an emerging trend identified as one that is transforming the society and the business world today (Lee et al., 2018); in the sense, that it is being recognized as a phenomenon identified to disrupt traditional industries such as the impact of Airbnb on hotel industry or that of on demand ridesharing services such as Uber on the transportation sector (Trenz et al., 2018) [20]

Leismann et al (2013) [21] point at a shift towards a resource saving consumption culture wherein consumers are preferring renting, bartering and exchanging over ownership (Tussyadiah and Pesonen, 2016) [22]. Collaborative consumption defined as "people coordinating the acquisition and distribution of a resource for a fee or other compensation" (Belk, 2014, p. 1579) [16] of which peer to peer accommodation such as Airbnb is a part of, can present challenges to present business models with Zervas, et al. (2017) [23] having estimated the increase in Airbnb listing leading to a decrease in quarterly hotel revenues in the state of Texas, mainly with budget hotels being affected, leading the authors to conclude, peer-to-peer markets, collectively known as the sharing economy, have emerged as alternative suppliers of goods and services traditionally provided by long-established industries.

That ownership is no longer the ultimate expression of consumer desire (Chen 2009; Marx 2011) [24] is evident with the observation that instead of buying and owning things, consumers want access to goods and prefer to pay for the experience of temporarily accessing them with observers noting during the last decade that markets are giving way to networks, and alternative modes of acquisition and consumption are emerging beside ownership (Bardhi and Eckhardt, 2012) [25].

Published By: 
Car sharing may be defined as gaining access to cars for short term periods by paying for use (Bardhi and Eckhardt, 2012)[25]. While earlier, ownership was considered superior to renting, the last decade has witnessed increase in access based consumption due to factors such as digital technology acting as an enabler; a shift in the sociocultural politics of consumption wherein access, in comparison with ownership is no longer perceived as an inferior mode of consumption; ownership and attachment to things become problematic in an increasingly 'liquid society' as well as access based consumption providing consumers with increased flexibility, adaptability, along with coinciding with economic crisis, such consumption mode is an apt alternative to the increases in the cost of acquiring and maintaining associated with ownership (Bardhi and Eckhardt, 2012)[25]. Puschmann and Alt (2016) add convenience and lower prices to have attracted consumers towards the sharing of resources in place of traditional ownership mode (Camilleri and Neuhofer,2017) [26]. These developments of a preference towards sharing economy facilitated by platforms such as Airbnb/Uber have led to traditional sectors such as the traditional hospitality sector facing high competition.

\section{B. Theoretical Underpinnings of the Study:}

Two theories were found to be suitable to be used for the current study: The Service Dominant theory (Vargo and Lush, 2004; 2008) [27] and The Practice Theory (Warde 2005, Reckwitz 2002)[28] [29]. We found both theories to provide the base for our argument and initial observation that consumers in India are moving towards adopting sharing economy over ownership in terms of cars. In the next sections, these two theories are discussed on the sharing economy concept.

\section{Service Dominant logic and ride sharing}

The service dominant logic (Vargo and Lush, 2004; 2008) [27] allows to draw comparisons between car sharing and car ownership. The S D logic has been used in the context of sharing economy (Camilleri and Neuhofer, 2017; Johnson and Neuhofer, 2017; Frey et al., 2017) [26] [30] [31]such that adhering to the SD logic, in sharing economy modes of consumption, the customer is not a passive recipient,in fact consumers is primarily interested in using resources to obtain value and value being recognized as being present not in the object of consumption but in the experience of consumption (Camilleri and Neuhofer, 2017) [27] and whereby value is created through a collaborative effort between consumers and producers (Johnson and Neuhofer, 2017)[26].

Sharing economy is primarily facilitated through IT enabled digital platforms for which, value creation involves facilitation of external interactions between different parties such that value is generated via a complex collaborative networked ecosystem, by which a service centred view may be applied for understanding value creation and innovation in the context of the sharing economy, including peer to peer ridesharing. The three elements grounded in the S-D logic, viz.: service ecosystem, service platforms and value cocreation are all embedded in the sharing economy, including in the case of P2P ridesharing (Frey et al., 2017)[31].
At the base of the assumptions underlying the S-D logic, consumers are primarily interested in using, rather than owning resources, value being recognized as being present in the experience and not in the object of consumption (Camilleri and Neuhofer,2017) [26].

\section{Practice Theory}

The Practice refers to the collection of activities performed by practitioners which is a combination or a connected web of elements: rules and regulations clubbed with instructions, competencies and motivations and clear understanding of things (Warde 2005, Reckwitz 2002) [28] [32]. The practice are unique, personalized and are of different styles. The Practice styles directs the service system towards value creation efforts specifically .Some degree of changes incorporated in the interaction styles while performing the service activities (Mc Coll-Kennedy et al 2012) [33]. Different authors have identified varied number of practicing styles, for instance Mc Coll-Kennedy 2012, indicated majorly five practicing styles (passive compliance, team management, partnering, insular controlling, and pragmatic adapting). Though not in the same line, Chandler (2016) came out with a four-practice style which includes social-modified, social-extant, Individual-extant and individual-modified), both the styles are more commonly prevailing in the Health care, and Arts and crafts contexts. Earlier studies have evidenced (Hazee et al 2017: Huber;2017: Lachuaud 2017)[34] use of practice theory in order to investigate on sharing economy(Schoretal,2016 Herbert and Collin -Lachaud 2017) [35].

From the above theories, it would be reasonable to assume, as an extension to the context of this study, that consumers would prefer using resources - a car in this caseto obtain value identifying value present in the experience of using the resource, not in owning it (S-D logic). Further, as per the practice theory, consumers would also prefer sharing economy for the elements embedded in the sharing economy that help create the value consumers seek.

\section{E. Car Sharing in India -influence on commuting} behavior in India:

News articles have been recognized as an important source of academic publishing (Meyer, 2018)[36]. With the geography of the news publications in relation to the institution wherein the academic study in being carried out influences the choice of news publications (Meyer, 2018)[36]; the authors of this study have assessed and included relevant information from news sources, which are well reputed in the country, as per the judgement of the authors and the expert opinion of other academicians. As such, well-regarded sources that include business periodicals such as 'The Economic Times'; 'Livemint'; 'Business Standard'; 'Hindu Businessline'; 'Financial Express' have been considered. The information from these periodicals has been used primarily as indicative of the trends in car sharing in India, as a precursor to the study. Further, with hardly any research carried out in the area, particularly in India, it was 
felt information from these periodicals would help with an understanding of the developing trends in the country.

Car ownership and the auto sector are witnessing disruption due to the increasing traffic congestion and commute times with the increasing pervasiveness of cabhailing, car pooling and ride sharing options such as Uber and Ola in India (Goyal, 2018) [7] Further, the presence of services such as Uber and Ola have begun to reflect in car sales with metro India preferring theses services to purchasing a second or third car (Halan, 2018) [37]. Additionally, Hyundai Motors backed car rental service, Revv as well as a new subscription-based car service named OPEN, along with Uber and Ola have intensified the competition against car ownership (Malik, 2018)[38] As per an Uber commissioned BCG report, over 79 percent potential car buyers would refrain from buying a car if ridesharing matches car ownership for affordability and convenience (www.newindianexpress.com, 2018)

The primary reasons for this preference of car rentals over ownership as reported include rise in traffic congestion, pollution concerns, long commute, parking challenges, reduction in terms of time, money and personal effort of negotiating traffic and parking as well as the associated convenience and flexibility that car rentals allow over ownership [Goyal (2018); ,Halan (2018); Goyal (2019)][7][37]

\section{RESEARCH METHODOLOGY \& RESULTS}

\section{A. Hypothesis Development}

Based on literature that suggests sharing economy is being increasingly adopted for various reasons; that the sharing economy is causing an impact on the traditional industries; the theories that provide a basis for the increase in adoption of the sharing economy services as well as based on reports from reputed news periodicals of the country, we assume car sharing services would be preferred over car ownership over time. Accordingly, we assume, as ride sharing services increase, car sales would decline over time. A country's GDP has been recognized as important determinant of national automobile ownership (Prevedourous and An, 1999)[39]. We accordingly assume, the relationship between GDP of India and car sales in India to change over a period of time upon the introduction of the country's ride sharing services in the form of Ola and Uber.

Specifically, we hypothesise that the impact of GDP on car sales in India in the pre-ride sharing era in the country would differ significantly from the impact of GDP on car sales in India on the introduction of ride sharing services such as Ola and Uber. This change - in the form of reduced impact of GDP on car sales in the country, would be due to the introduction of ride sharing services in India which should be evident with comparisons made between the pre and post periods of car sharing services in the country.

H1: The impact of GDP on car sales in India in the period after the introduction of Ola and Uber would be significantly lower than the impact of GDP on car sales in India in the pre-ride sharing era in the country.

\section{B. Data Analysis:}

Ola - a peer to peer ride sharing services started in India in December 2010. Uber services on the other hand started in August 2013 in India.

This study, being first of its kind, in the best knowledge of the authors, in the context of India, while exploratory, provides a rudimentary analysis wherein the study examines whether car sales in the country have indeed changed significantly with the introduction of car ride-sharing services, such as Ola and Uber in the country.

To do such an analysis, this study assess historical data of passenger car sales in the country. All the data regarding car sales and GDP have been taken from the government official data source website data.gov.in. The data provided on the website is till 2011-12. Car sales data of the later years are taken from the website ceicdata.com, the global economic data indicator providers. The GDP data for later years have been derived from the reported growth rates post 2012.The purpose of looking at the above mentioned data is to examine whether passenger case sales underwent a change in the aftermath of the ride sharing services growth in the country. As mentioned, our hypothesis is that passenger car sales underwent a reduced growth post introduction of ride sharing services in India. Figures 1 and 2 below provide data on car sales in India. The Figure 1 which shows data on car sales shows a decline post 2011 and sales seem to be picking up gradually in the later years. To confirm this, when we look at Figure 2 which tracks the growth rates of car sales, one sees that the growth rates show more defined changes post 2011-12. This raises the question as to whether the economy has undergone a structural shift post the introduction of ride sharing services in 2011-12. To answer this question, we look at the relationship between growth in GDP and growth in car sales.

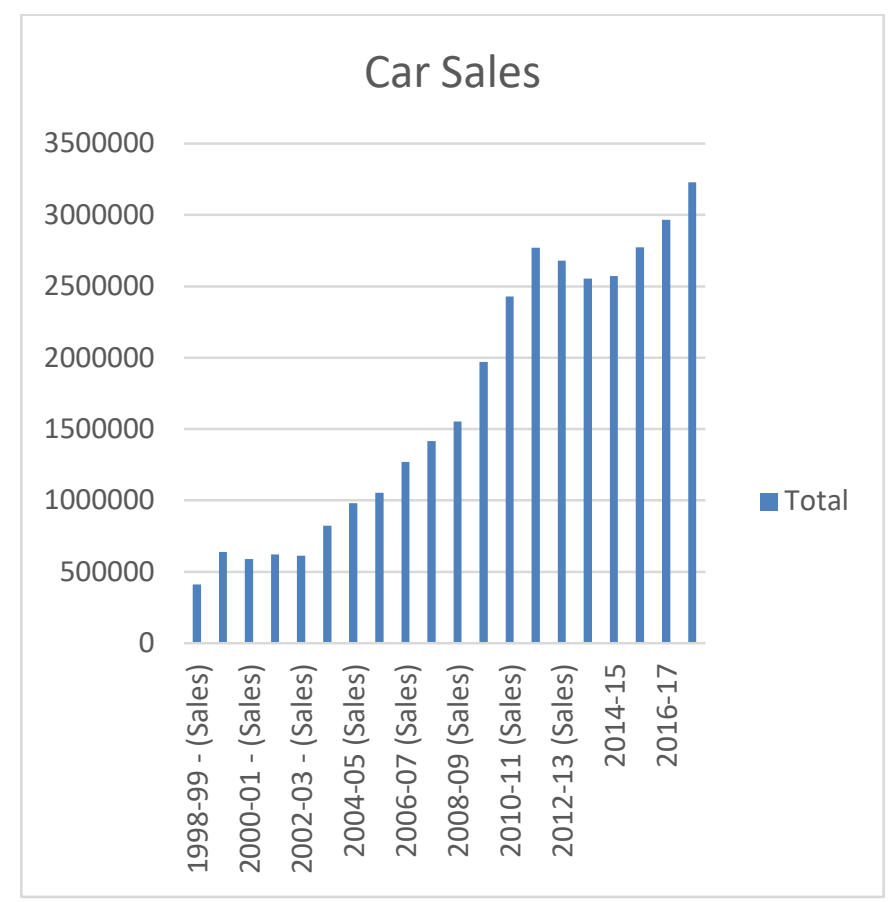




\section{Growth in Car sales}

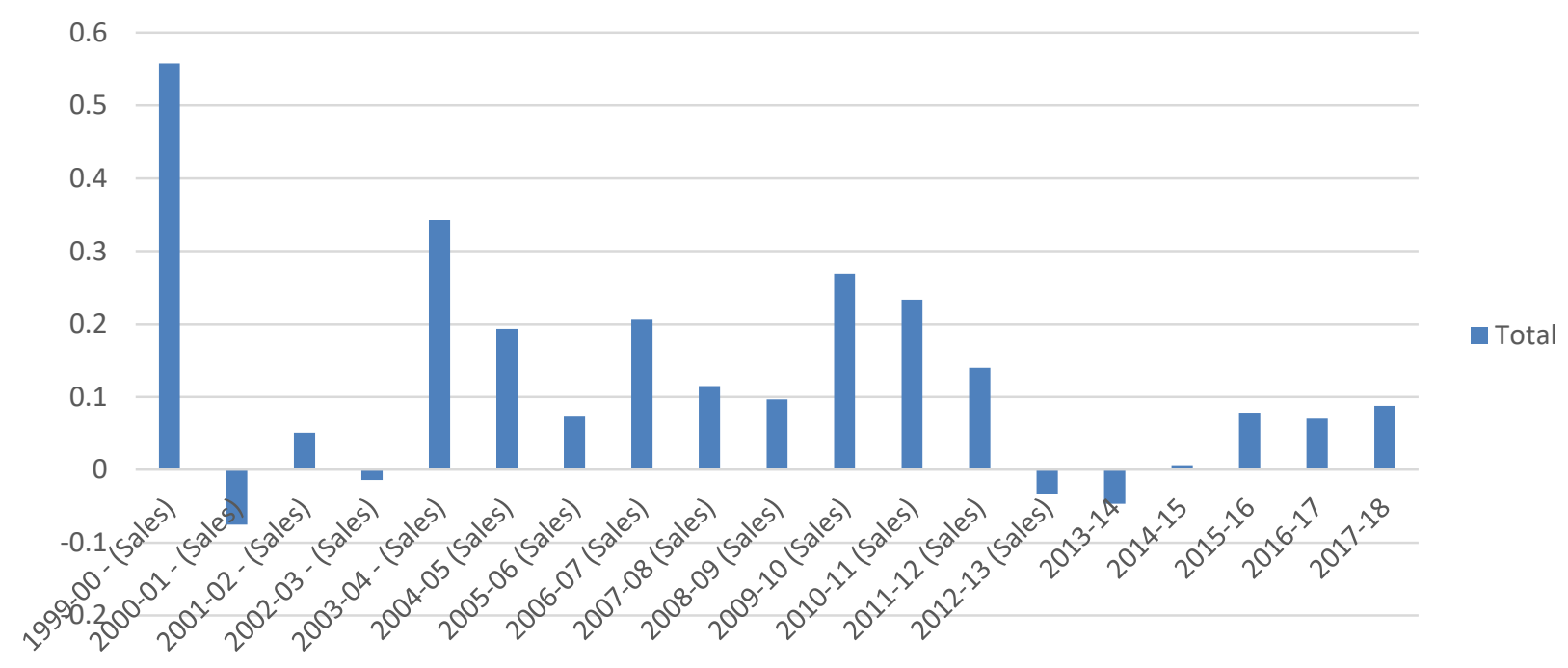

The Centre for Automotive Research in USA recorded the impact of growth in automobile sector on the GDP growth rates across all its states. ["Contribution of Automotive Industry to the Economy of All Fifty States and the United States", Centre for Automotive Research, 2015,www.cargroup.org].

When considering the above data of historical car sales in India, while, one can see some amount of change, the question whether this change is statistically significant or not will tell us something more about the nature of this change. To do so, this study uses an econometric tool-the Chow test. The Chow method (Chow, 1960)[40] was originally used to compare financial data from two different time periods, the method allowing the determination of whether or not newly collected data exhibits the same relationship between the dependent and the independent variables in the previous data (Lee, 2008) [41]. The Chow statistic shows the ratio of the difference between the two residual sums of squares for the two linear regressions, adjusted for the corresponding degrees of freedom, to test the equality between the sets of coefficients in two linear regressions (Lee, 2008)[41]

Similarly, this study used the Chow test to draw two linear regressions to compares data related to car sales with a comparison with GDP over two periods of time: 1999-00 to 2010-11 and the other from 2011-12 to 2017-18.

With GDP being recognized as important determinant of national automobile ownership (Prevedourous and An, 1999)[39], this study related car sales with GDP levels in India. GDP at constant prices have been considered for the same. Since the car growth rates graph shows 2011-12 as the year when sales have undergone a shift and also due to the fact that Ola services were introduced in India in 2010 December, we accordingly divide the entire period from $1999-00$ to $2017-18$ into two sub period. One from 1999-00 to $2010-11$ and the other from $2011-12$ to $2017-18$ and try to see whether the relationship between car sales and GDP hold in both the periods.

For the first sub period from 1999-00 to 2010-11, we get the following regression equation:
Car Sales $=-953989(\mathrm{t}=-8.3)+0.64$ GDP $(\mathrm{t}=18.58)$; $\mathrm{R}^{2}=0.96$

For the second sub period from 2011-12 to 2017-18, we get the following regression equation:

Car Sales $=1552028(t=3.3)+0.19(t=2.69) ; \mathrm{R}^{2}=0.6$

As we can observe, both equations are statistically significant. However, in the first sub period, a unit change in GDP brings about a change of 0.64 in car sales while in the second sub period, the same change in GDP brings about a change of 0.19 units in car sales. To see whether this change is statistically significant we employ a chow test. The chow ratio is an $\mathrm{F}$ ratio where one compares the residual sum of squares of two periods regression with a combined regression for both the periods. The assumption is that if there has been no structural change in the two periods, then the $F$ ratio will be statistically insignificant.

We get a chow statistic of 19.89 which is significant at a $\mathrm{p}$ value of 0.01 . Thus, we can say that there has been a structural change in this relationship in the two periods considered above, which supports stated hypothesis $\mathrm{H} 1$.

\section{CONCLUSIONS AND DISCUSSION}

Both the growth rates in car sales and the relationship between GDP and car sales point towards a structural shift. The structural shift is statistically significant is also brought about by the use of chow ratio. It is however possible that there may be other factors that may have played a role as well. However, there is ample ground based on data now to claim that this structural shift coincides with the introduction of car sharing services in India.

Ride sharing services, in the form of Ola and Uber are clearly being chosen by consumers in India: the factors for this preference include traffic congestion, pollution, economic benefits as well as convenience and flexibility. Additionally, while car ownership was considered a status symbol in India, this belief is changing [1].

With parking difficulties being one of the major reasons for consumers to travel via ride sharing apps, Engel Yan and

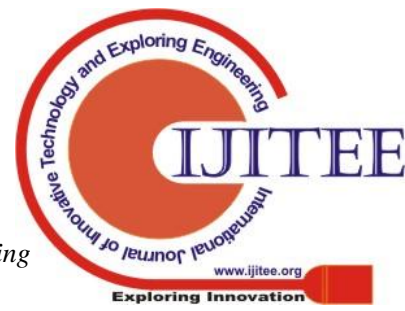


Passmore (2013) [42]offer policy recommendations that could address this issue.

For auto majors, if the trend of Indian consumers preferring car sharing to car ownership continues, leading to continuation of the dampening of car sales growth as in figure 2 above, the trend supports the strategic direction auto majors are taking in the country by introducing subscription based access to various car models : examples are Revv and OPEN (7).

While this study deliberates on whether car sharing would overtake car ownership in India, bringing forth the trend as it is still taking shape, it is early to deliver conclusive results. Being an exploratory study, further studies are required, that encompass empirical studies including surveys, especially, with the younger Indian consumers on their preferences between car sharing and car ownership. Such studies should include the tier 2 and tier 3 cities of the country- towns which are fast growing but less developed that metropolitans such as Pune and other larger cities, where a higher prevalence of ride sharing is observed. This would aid in generalization of results that are more conclusive in nature.

\section{REFERENCES}

1. Soltani, A., Deng, A., Taheri, A., Mirzababaei, M., \& Vanapalli, S. K. (2019). Swell-Shrink Behavior of Rubberized Expansive Clays During Alternate Wetting and Drying. Minerals, 9(4), 224.

2. Nahon, P., Layese, R., Bourcier, V., Cagnot, C., Incidence of hepatocellular carcinoma after direct antiviral therapy for $\mathrm{HCV}$ in patients with cirrhosis included in surveillance programs. Gastroenterology, 155(5), 1436-1450.

3. Schmidt, R. A., Lee, T. D., Winstein, C., Wulf, G., \& Zelaznik, H. N. (2018). Motor control and learning: A behavioral emphasis. Human kinetics.

4. Liao, Y., \& Foster, M. S. (2018). Dephasing Catastrophe in $4-\varepsilon$ Dimensions: A Possible Instability of the Ergodic (Many-Body-Delocalized) Phase. Physical review letters, 120(23), 236601.

5. MacMillan, D., \& Demos, T. (2015). Uber valued at more than $\$ 50$ billion. Wall Street Journal.

6. Chao, H. P., \& DePillis, M. (2013). Incentive effects of paying demand response in wholesale electricity markets. Journal of Regulatory Economics, 43(3), 265283.

7. Goyal, P., \& Ferrara, E. (2018). Graph embedding techniques, applications, and performance: A survey. Knowledge-Based Systems, 151, 78-94.

8. Willett, W., Rockström, J., Loken, B., Springmann, M., Lang, T., Vermeulen, S., ... \& Jonell, M. (2019). Food in the Anthropocene: the EAT-Lancet Commission on healthy diets from sustainable food systems. The Lancet, 393(10170), 447-492.

9. Goyal, P., \& Ferrara, E. (2018). Graph embedding techniques, applications, and performance: A survey. Knowledge-Based Systems, 151, 78-94.

10. Kumar, S., Stecher, G., Li, M., Knyaz, C., \& Tamura, K. (2018). MEGA X: molecular evolutionary genetics analysis across computing platforms. Molecular biology and evolution, 35(6), 1547-1549. the sharing economy: Estimating the impact of Airbnb on the hotel industry, Boston U. School of Management Research Paper Series, 2013-6. Marcellin, P., Guyader, D., ... \& Zoulim, F. (2018).

11. Zervas, G., Proserpio, D., \& Byers, J. (2014). The rise of

12. Camilleri, J., \& Neuhofer, B. (2017). Value co-creation and co-destruction in the Airbnb sharing economy. International Journal of Contemporary Hospitality Management, 29(9), 2322-2340.

13. Durgee, J. F., \& Colarelli O'Connor, G. (1995). An exploration into renting as consumption behavior. Psychology \& Marketing, 12(2), 89-104.

14. Lovelock, C., \& Gummesson, E. (2004). Whither services marketing? In search of a new paradigm and fresh perspectives. Journal of service research, 7(1), 2041.

15. Chen, H. Y., Hou, J., Zhang, S., Liang, Y., Yang, G., Yang, Y., ... \& Li, G. (2009). Polymer solar cells with enhanced open-circuit voltage and efficiency. Nature photonics, 3(11), 649.

16. Belk, R. (2014). You are what you can access: Sharing and collaborative consumption online. Journal of business research, 67(8), 1595-1600.

17. Gansky, L. (2010). The mesh: Why the future of business is sharing. Penguin.

18. Rifkin, J. (2000). The age of access: how the shift from ownership to access is transforming modern life (p. 30). London: Penguin.

19. Writing Group Members, Lloyd-Jones, D., Adams, R. J., Brown, T. M., Carnethon, M., Dai, S., ... \& Gillespie, C. (2010). Executive summary: heart disease and stroke statistics-2010 update: a report from the American Heart Association. Circulation, 121(7), 948-954.

20. Bossetta, M., Segesten, A. D., \& Trenz, H. J. (2018). Political participation on Facebook during Brexit. Journal of Language and Politics, 17(2), 173-194.

21. Leismann, K., Schmitt, M., Rohn, H., \& Baedeker, C. (2013). Collaborative consumption: towards a resourcesaving consumption culture. Resources, 2(3), 184-203.

22. Tussyadiah, I. P., \& Pesonen, J. (2016). Impacts of peerto-peer accommodation use on travel patterns. Journal of Travel Research, 55(8), 1022-1040.

23. Zervas, G., Proserpio, D., \& Byers, J. W. (2017). The rise of the sharing economy: Estimating the impact of Airbnb on the hotel industry. Journal of marketing research, 54(5), 687-705.

24. Chen, L., \& Novy-Marx, R. (2011). An alternative threefactor model. Available at SSRN 1418117.

25. Bardhi, F., \& Eckhardt, G. M. (2012). Access-based consumption: The case of car sharing. Journal of consumer research, 39(4), 881-898.

26. Camilleri, J., \& Neuhofer, B. (2017). Value co-creation and co-destruction in the Airbnb sharing economy. International Journal of Contemporary Hospitality Management, 29(9), 2322-2340.

27. Vargo, S. L., \& Lusch, R. F. (2008). Service-dominant logic: continuing the evolution. Journal of the Academy of marketing Science, 36(1), 1-10.

28. Warde, A. (2005). Consumption and theories of practice. Journal of consumer culture, 5(2), 131-153.

29. Reckwitz, A. (2002). Toward a theory of social practices: A development in culturalist theorizing. European journal of social theory, 5(2), 243-263.

30. Johnson, A. G., \& Neuhofer, B. (2017). Airbnb-an exploration of value co-creation experiences in Jamaica. International Journal of Contemporary Hospitality Management, 29(9), 2361-2376.

31. Frey, C. B., \& Osborne, M. A. (2017). The future of employment: How susceptible are jobs to computerisation?. Technological forecasting and social change, 114, 254-280. 
32. Reckwitz, A. (2002). Toward a theory of social practices: A development in culturalist theorizing. European journal of social theory, 5(2), 243-263.

33. Tommasetti, A., Troisi, O., \& Vesci, M. (2015, June). Customer value co-creation: a conceptual measurement model in a Service Dominant Logic perspective. In Naples Forum on Service (Vol. 15, pp. 1-31).

34. Hazée, S., Van Vaerenbergh, Y., \& Armirotto, V. (2017). Co-creating service recovery after service failure: The role of brand equity. Journal of Business Research, 74, 101-109.

35. Herbert, M., \& Collin-Lachaud, I. (2017). Collaborative practices and consumerist habitus: An analysis of the transformative mechanisms of collaborative consumption. Recherche et Applications en Marketing (English Edition), 32(1), 40-60.

36. Raskob, G. E., van Es, N., Verhamme, P., Carrier, M., Di Nisio, M., Garcia, D., ... \& Meyer, G. (2018). Edoxaban for the treatment of cancer-associated venous thromboembolism. New England Journal of Medicine, 378(7), 615-624.

37. Naik, K., Chatterjee, A., Prakash, H., \& Kowshik, M. (2013). Mesoporous TiO2 nanoparticles containing Ag ion with excellent antimicrobial activity at remarkable low silver concentrations. Journal of biomedical nanotechnology, 9(4), 664-673.

38. Nogueira, R. G., Jadhav, A. P., Haussen, D. C., Bonafe, A., Budzik, R. F., Bhuva, P., ... \& Sila, C. A. (2018). Thrombectomy 6 to 24 hours after stroke with a mismatch between deficit and infarct. New England Journal of Medicine, 378(1), 11-21.

39. Prevedouros, P. D., \& Wang, Y. (1999). Simulation of large freeway and arterial network with CORSIM, INTEGRATION, and WATSim. Transportation Research Record, 1678(1), 197-207.

40. Chow, G. C. (1960). Tests of equality between sets of coefficients in two linear regressions. Econometrica: Journal of the Econometric Society, 591-605.

41. Lee, C., Wei, X., Kysar, J. W., \& Hone, J. (2008). Measurement of the elastic properties and intrinsic strength of monolayer graphene. science, 321(5887), 385-388.

42. Engel-Yan, J., \& Passmore, D. (2013). Carsharing and car ownership at the building scale: Examining the potential for flexible parking requirements. Journal of the American Planning Association, 79(1), 82-91.

\section{AUTHORS PROFILE}

Aditi Naidu has 9 years of teaching and research experience in the domain of Marketing. She has completed her Masters in Business (Marketing) from the University of Western Sydney, Sydney, New South Wales, Australia where she was awarded the Executive Dean's Certificate for Merit. Her research interests are in the areas of Services Marketing, Rural Marketing and Marketing Communications. She has presented several papers in the reputed International conferences.

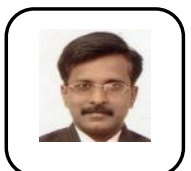

Kannan Rajagopal holds 15 years' experience of Teaching Management course both as Adjunct and Full Time Faculty in reputed Educational Institutions across the country. He has pursued his PhD in Marketing and $\mathrm{PhD}$ in HR and is associated currently with SCMHRD as a full time faculty, SIU Pune. He has presented research papers in reputed International Conferences in India and abroad. He has 2 decades of work experience in Automotive Marketing.

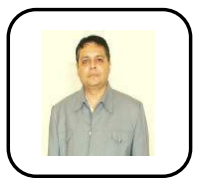

Manish Sinha is working as an Associate Professor at Symbiosis Centre for Management and Human Resource Development, SIU Pune and heads the department of 'Business Analytics'. He has more than 20 years of experience in teaching and research. His PhD is in the area of Monetary Policy and he teaches subjects like Economics and Econometrics, Financial Risk Management and Risk Analytics. He has published in both national and International Journals of repute and presented papers in prestigious conferences.

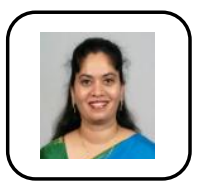

Vaishali Mahajan has 19 years of teaching Management subjects to the Masters(MBA) students. currently serves as Associate Professor and Head of the Department of Marketing Department at Symbiosis Centre for Management and Human Resource Development, Symbiosis International (Deemed), Pune. Her research interests' area includes service marketing, on line Marketing, and consumer Buying Behavior. She has presented several papers in the reputed International conferences. 